\title{
Role of the Cytoskeleton in Laminin Induced Mammary Gene Expression
}

\author{
JOANNE L. BLUM AND MAX S. WICHA* \\ Division of Hematology/Oncology, Department of Internal Medicine and Program in Cell \\ and Molecular Biology, Simpson Memorial Research Institute, University of Michigan, \\ Ann Arbor, Michigan 48109
}

The differentiation of rat mammary epithelial cells is characterized both by morphologic changes and by the expression of a group of milk protein genes. We have previously shown that by culturing these cells on the basement membrane glycoprotein laminin, the synthesis of the milk proteins, transferrin, $\alpha$-casein, and $\alpha$-lactalbumin is induced. In order to determine if this effect is mediated through the cytoskeleton, we have treated these cells with cytochalasin D and colchicine. Treatment with cytochalasin D or colchicine for $24 \mathrm{~h}$ inhibits the accumulation of $\alpha$-casein, transferrin, and $\alpha$-lactalbumin without significant effect on general protein synthesis. Pulse chase studies show that cytochalasin D does not alter the intracellular turnover of $\alpha$-casein or transferrin. Additionally, treatment with cytochalasin D causes an early (within $1 \mathrm{~h}$ ) increase in secretion of $\alpha$-casein and transferrin suggesting that the actin cytoskeleton provides a meshwork for secretory vesicles. The disruption of this network enhances the secretion of preformed proteins. However, long term $(24 \mathrm{~h})$ treatment with cytochalasin D inhibits synthesis of these milk proteins. Northern blot analysis indicates that treatment with cytochalasin D or colchicine inhibits the laminin induced increase in $\alpha$-casein, $\alpha$-lactalbumin, and transferrin mRNAs. These studies indicate that the major effect of the cytoskeleton on laminin induced milk protein gene expression occurs at the level of accumulation of mRNAs for these proteins. We conclude that the expression of laminin induced milk protein gene expression in primary rat mammary cultures depends on the integrity of the actin and microtubule cytoskeleton.

The normal differentiation of mammary epithelial cells is dependent on both soluble factors and the extracellular matrix (ECM). We have previously demonstrated that milk protein gene expression in primary rat mammary cultures is induced when these cells are plated on the basement membrane glycoprotein laminin (Blum, et al., 1987). Although we have found that this regulation occurs at both the mRNA and protein levels, the molecular mechanisms involved remain unknown. We have previously described a $68 \mathrm{kDa}$ cell surface receptor from murine fibrosarcoma cells (Malinoff and Wicha, 1983), macrophages (Huard et al., 1986) and neutrophils (Yoon et al., 1987) which binds laminin with specificity and high affinity $(\mathrm{Kd}=2 \times$ $\left.10^{-9} \mathrm{M}\right)$. Similar laminin binding proteins have been isolated from mammary cells (Terranova et al., 1983) and muscle cells (Lesot et al., 1983). We have also demonstrated that this cell surface receptor is capable of interacting with filamentous actin (Brown et al., 1983) and provided evidence that the interaction between the laminin receptor and the cytoskeleton is regulated by the binding of laminin (Cody and Wicha, 1986). Sugrue and Hay (1981) have shown that the addition of soluble laminin to corneal epithelial cells induces reorganization of the actin cytoskeleton.

Based on the above observations we hypothesized that the effects of laminin on mammary differentiation are mediated by the cytoskeleton. If this were the case then cytoskeletal disrupting agents should block milk protein gene expression induced by laminin. Therefore, we have investigated the effects of cytochalasin $D$ and colchicine on laminin induced milk protein mRNA and protein expression in primary rat mammary cultures. Cytochalasin D inhibits actin polymerization while colchicine prevents microtubule polymerization (Andreu and Timasheff, 1986; Brown and Spudich, 1979; Flanagan and Lin, 1980; MacLean-Fletcher and Pollard, 1980; Schliwa, 1982). We report that these cytoskeletal disrupting agents selectively inhibit laminin induced milk protein gene expression. These effects occur predominately at the level of steady state accumulation of mRNAs for these genes. These experiments demonstrate that the expression of laminin induced milk protein genes in primary rat mammary cultures depends on the integrity of the cytoskeleton. Based on these observations, we propose that the effect of laminin on mammary differentiation may be mediated by the cytoskeleton through changes in transcription and/or stabilization of specific mRNA species.

Received November 19, 1987; accepted January 23, 1988.

*To whom reprint requests/correspondence should be addressed.

Abbreviations: $\alpha$-LA, $\alpha$-lactalbumin; ECM, extracellular matrix. 


\section{MATERIALS AND METHODS \\ Mammary cell preparation and culturing conditions}

Mammary cells were isolated from perphenazine stimulated virgin female Sprague-Dawley rats by limited collagenase digestion, differential filtration, and differential attachment to tissue culture plastic, as previously described by Wicha et al. (1982). After 6 days in culture, the cells were treated with cytoskeletal inhibitors for $24 \mathrm{~h}$. Cytochalasin D (Sigma Chemical Co., St. Louis, MO) was diluted in ethanol to $2 \mathrm{mM}$, stored at $-20^{\circ} \mathrm{C}$ and added to the cultures to a final concentration of $2 \mu \mathrm{M}$. Colchicine (Sigma Chemical Co.) was diluted in ethanol to $1 \mathrm{mM}$ and stored at $-20^{\circ} \mathrm{C}$ and added to the cultures to a final concentration of $1 \mu \mathrm{M}$. Equivalent amounts of ethanol were added to the control cultures.

\section{Preparation of laminin}

Laminin was prepared from the EHS tumor as described by Timpl et al. (1979) and its purity assayed by SDS-PAGE (Laemmli, 1970) and silver staining (Morrissey, 1981). Laminin was stored at $-70^{\circ} \mathrm{C}$ prior to use, diluted in water at $5 \mu \mathrm{g} / \mathrm{cm}^{2}$ and dried onto $35 \mathrm{~mm}$ tissue culture dishes (Becton Dickinson, Oxnard, CA). Approximately 2-5\% of the added laminin bound to the dishes as demonstrated by quantitation using [ $\left.{ }^{125} \mathrm{I}\right]-$ laminin which was prepared as described by Malinoff and Wicha (1983).

\section{Immunoprecipitation of milk proteins}

Cultures were incubated in methionine-free medium containing the cytoskeletal inhibitors for one hour at $37^{\circ} \mathrm{C}$, then labeled with $250 \mu \mathrm{Ci} / \mathrm{ml}\left[{ }^{35} \mathrm{~S}\right]$-methionine [ $>1000 \mathrm{Ci} / \mathrm{mmol}]$ for one hour. The medium was removed, deoxycholate and Nonidet P40 were added to $1 \%$ and $0.5 \%$, respectively. The cells were washed three times with $0.14 \mathrm{M} \mathrm{NaCl}, 50 \mathrm{mM}$ Tris- $\mathrm{HCl}, \mathrm{pH} 7.4$ then lysed with $25 \mathrm{mM}$ Tris- $\mathrm{HCl}, 50 \mathrm{mM} \mathrm{NaCl}, 1 \%$ Nonidet

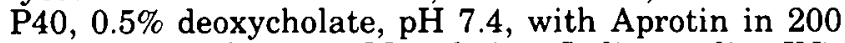
units/ml (Boehringer Mannheim, Indianapolis, IN). Plates were scraped with a rubber policeman and the lysate was centrifuged at $10,000 \mathrm{~g}$ for $30 \mathrm{~min}$ and the supernatants removed. The supernatants were brought to an equal volume with the lysis buffer and stored at $-70^{\circ} \mathrm{C}$. All procedures were performed at $4^{\circ} \mathrm{C}$. TCA precipitation was performed on duplicate aliquots from each sample of media or cell lysate. Equivalent TCA precipitable counts were immunoprecipitated by an immune complex method described by Blum et al. (1987), and modified from Terhorst et al. (1981) and Tolleshaug et al. (1982). A rabbit anti-rat milk antibody characterized by Blum et al. (1987) was utilized for these immunoprecipitation studies. Samples were electrophoresed on $13.5 \mathrm{~cm} 10 \%$ slab gels, treated with En3Hance (Dupont, New England Nuclear, Boston, MA), dried, and exposed at $-70^{\circ} \mathrm{C}$ to Kodak XAR-5 film. In order to quantitate the radioactivity in the immunoprecipitated proteins, the bands were cut from the filters, dissolved in $\mathrm{H}_{2} \mathrm{O}_{2}$ at $100^{\circ} \mathrm{C}$ for $2 \mathrm{~h}$, solubilized in Beckman Ready-Solv-MP and counted in a scintillation counter. Background counts from a region of the filter without detectable protein bands were subtracted from the samples.

\section{Pulse-chase immunoprecipitation experiments}

Equivalent numbers of cells on laminin coated dishes were incubated in methionine-free medium for $1 \mathrm{~h}$, then pulsed with $200 \mu \mathrm{Ci} / \mathrm{ml}\left[{ }^{35} \mathrm{~S}\right]$-methionine for $1 \mathrm{~h}$. Cultures were washed with medium supplemented with $4 \mathrm{mg} / \mathrm{ml}$ methionine (Sigma Chemical Co.), then chased with medium containing $4 \mathrm{mg} / \mathrm{ml}$ methionine for the indicated times. During the chase, half of the dishes were treated with cytochalasin D $2 \mu \mathrm{M}$ and half were untreated. Medium and cell lysates were harvested, immunoprecipitated, electrophoresed, dried, and analyzed as described above.

\section{Measurement of $\alpha$-lactalbumin}

Cells were plated on tissue culture plastic or laminin, treated with cytoskeletal inhibitors for $24 \mathrm{~h}$, and the medium removed. Unattached cells were pelleted by centrifugation at $2000 \mathrm{~g}$ for $5 \mathrm{~min}$ at $4^{\circ} \mathrm{C}$ and the medium stored at $-20^{\circ} \mathrm{C}$. Cell lysates were prepared as described above. A radioimmunoassay on 4 to 6 replicate dishes was performed as previously described by Wicha et al. (1982).

Cell numbers were determined by removing the cells with $0.25 \%$ trypsin $0.1 \%$ EDTA (K.C. Biological, Lenexa, KS) and counting trypan blue excluding cells in a hemocytometer.

\section{Immunofluorescence microscopy}

Fluorescent staining of f-actin: Mammary cells plated on laminin coated or uncoated tissue culture chamber slides (Miles Scientific, Naperville, IL) were treated with cytoskeletal inhibitors for $24 \mathrm{~h}$. The cells were fixed in $3.7 \%$ formaldehyde, permeabilized in $0.02 \%$ Triton X-100 in PBS, washed and stained with rhodamine conjugated phalloidin (Molecular Probes, Eugene, $O R$ ) as described by the manufacturer.

Fluorescent staining of tubulin: The cells were fixed in $2 \%$ paraformaldehyde in PBS, washed with $0.1 \mathrm{M}$ glycine in PBS, permeabilized with $0.02 \%$ Triton X-100 in PBS, and incubated with a rabbit polyclonal antibody directed against sheep tubulin (Miles Scientific, Naperville, IL) for $1 \mathrm{~h}$ at $37^{\circ} \mathrm{C}$. The antibody was diluted 1:10 in PBS with $10 \%$ goat serum. The cells were washed in PBS and then incubated for $1 \mathrm{~h}$ at $37^{\circ} \mathrm{C}$ with goat anti-rabbit fluorescein conjugated second antibody diluted 1:20 in PBS/10\% goat serum. The cells were washed with PBS and mounted in glycerol with $0.1 \%$ N-N-dimethyl-P-phenylenediamine dihydrochloride (Sigma Chemical Co.). Negligible staining was observed in control cells incubated in PBS $/ 10 \%$ goat serum without primary antibody. The slides were photographed on a Leitz epifluorescence microscope.

\section{RNA isolation}

Total RNA was isolated from virgin mammary glands and from the cultured cells using a guanidium isothiocyanate/cesium chloride method described by Chirgwin et al. (1979). The RNA was treated with RNase free DNase (Promega, Madison, WI), phenol extracted, ethanol precipitated, and quantitated by spectrophotometry. 


\section{Northern blot analysis}

RNA was size fractionated on formaldehyde-agarose gels, transferred to nitrocellulose as described by Maniatis et al. (1982) and hybridized to ${ }^{32} \mathrm{P}$ nick translated cDNAs for rat $\alpha$-casein, rat transferrin, and mouse $\alpha$-lactalbumin as Blum et al. (1987) have described. The plasmid cDNA for rat $\alpha$-casein characterized by Richards et al. (1981a,b) was provided by Jeffrey Rosen. The plasmid cDNA for transferrin was provided by Lola Reid and the plasmid cDNA for $\alpha$-lactalbumin by M. R. Banerjee. The cDNA inserts were excised from the plasmid DNA by cutting with the appropriate restriction endonuclease and isolated by electrophoresis and electroelution. The cDNA insert sizes are: $\alpha$-casein, $1.06 \mathrm{~kb}$ (PSTI/HpaII), transferrin, 0.83 and $0.69 \mathrm{~kb}$ (PSTI), and $\alpha$-LA, $0.6 \mathrm{~kb}$ (PSTI). $100 \mathrm{ng}$ of cDNA insert was labeled by nick translation to a specific activity of $2-5 \times 10^{8} \mathrm{cpm} / \mu \mathrm{g}$ of DNA. The filters were prehybridized, hybridized, and washed as Blum et al. (1987) have described. The intensity of the bands was quantified by densitometry in the linear range of film detection and by integrating the area under the peaks.

\section{RESULTS \\ Effects of cytoskeletal disrupting agents on milk protein expression}

We have previously shown that the culture of rat mammary cells on a substratum of the basement membrane glycoprotein laminin induces the expression of the milk proteins $\alpha$-casein, transferrin, and $\alpha$-lactalbumin ( $\alpha-\mathrm{LA})$. To determine whether this induction requires an intact cytoskeleton, we examined the effects of the cytoskeletal inhibitors, cytochalasin D and colchicine, on the expression of these proteins.

\section{$\alpha$-Casein and transferrin}

Immunoprecipitation utilizing anti-milk antibodies was used to detect $\alpha$-casein and transferrin in primary rat mammary cultures. Six day cultures on laminin or tissue culture plastic substratum were treated with either cytochalasin $\mathrm{D}$, colchicine or medium (control), pulsed with $\left[{ }^{35} \mathrm{~S}\right]$-methionine and $\alpha$-casein and transferrin assayed by immunoprecipitation. $\alpha-1$ and $\alpha-2$ caseins are calcium binding phosphoproteins of 43 and $41 \mathrm{kD}$ and constitute a major component of milk. Transferrin, another milk component, serves as an iron binding protein and growth factor. As shown in Figures 1 and 2 , in the absence of cytoskeletal inhibitors, $\alpha$-casein expression is induced approximately 7 to 10 -fold on a laminin substratum compared to tissue culture plastic. Treatment of laminin based cultures with either cytochalasin D or colchicine reduced the level of expression of $\alpha$-casein to levels below that detected in cultures on plastic dishes in the absence of cytoskeletal inhibitors. Synthesis and secretion of transferrin induced by laminin were reduced by cytochalasin D or colchicine treatment (Fig. 1 and $2 b$ ) to levels comparable or to below that detected on tissue culture plastic in the absence of these inhibitors. The degree of inhibition of transferrin on laminin is greater than on plastic. Secretion of transferrin on laminin in the presence of cytochalasin D or colchicine is nearly completely inhibited whereas the transferrin band remains faintly detectable on plastic (see Fig. 1a,c). The induction of $\alpha$-casein by laminin is greater than that of transferrin. Similarly, the inhibition by cytochalasin D and colchicine is greater for $\alpha$-casein than for transferrin. The results of several immunoprecipitation experiments are summarized in Figure $2 a, b$ and demonstrate that the induction of both $\alpha$-casein and transferrin by laminin is abrogated by cytochalasin D or colchicine treatment.

\section{$\alpha$-Lactalbumin production}

We have previously shown that laminin is also able to induce the production of $\alpha-\mathrm{LA}$, a $20-21 \mathrm{kDa}$ protein co-factor for galactosyltransferase which is expressed in the mammary gland in vivo during lactation. The effect of cytochalasin D and colchicine on the expression of $\alpha$-LA as detected by radioimmunoassay is shown in Figure 3. In the absence of inhibitors, laminin induces $\alpha$-LA accumulation 4 to 5 fold compared to tissue culture plastic. Cytochalasin D or colchicine reduces the expression of $\alpha$-LA on a laminin substratum to levels comparable to that detected on tissue culture plastic.

\section{Specificity of protein inhibition}

The above experiments demonstrated that cytochalasin D or colchicine reduced the expression of milk protein genes induced by laminin. In order to characterize the specificity of these effects, we examined the effect of these cytoskeletal inhibitors on total protein synthesis. Total protein synthesis was quantitated by TCA precipitation of $\left.{ }^{35} \mathrm{~S}\right]$-methionine labeled cultures and further examined by SDS-PAGE. The results of several TCA precipitation experiments are summarized in Figure 4. Cytochalasin D treatment has no significant effect on total protein synthesis as assessed by TCA precipitable counts in the cell layer or medium. Colchicine treatment reduced total protein synthesis by 10 to $30 \%$ compared to that of untreated controls. In both cases, the degree of inhibition of total protein synthesis was far less than the degree of inhibition of milk protein synthesis.

In order to further characterize the proteins affected by cytoskeletal inhibitors, we analyzed total proteins by SDS-PAGE. As can be seen in Figure 5, the accumulation of the majority of proteins in primary mammary cultures is unaffected by cytochalasin $D$ or colchicine treatment. This was further confirmed by two-dimensional gel electrophoresis analysis of synthesized proteins (data not shown). Although these proteins are not specifically identified, protein electrophoresis indicates that most synthesized proteins appear to be unaffected by cytochalasin $\mathrm{D}$ or colchine. Taken together, these experiments demonstrate that the inhibition of milk protein gene expression by cytoskeletal disrupting agents is not the result of general inhibition of total protein synthesis. Furthermore, these experiments suggest that the requirements for an intact cytoskeleton for gene expression shows some degree of specificity for laminin induced milk protein genes.

\section{Effect of cytoskeletal inhibitors on protein turnover and mRNA accumulation}

Our previous studies indicated that laminin effects on milk protein gene expression resulted from regula- 

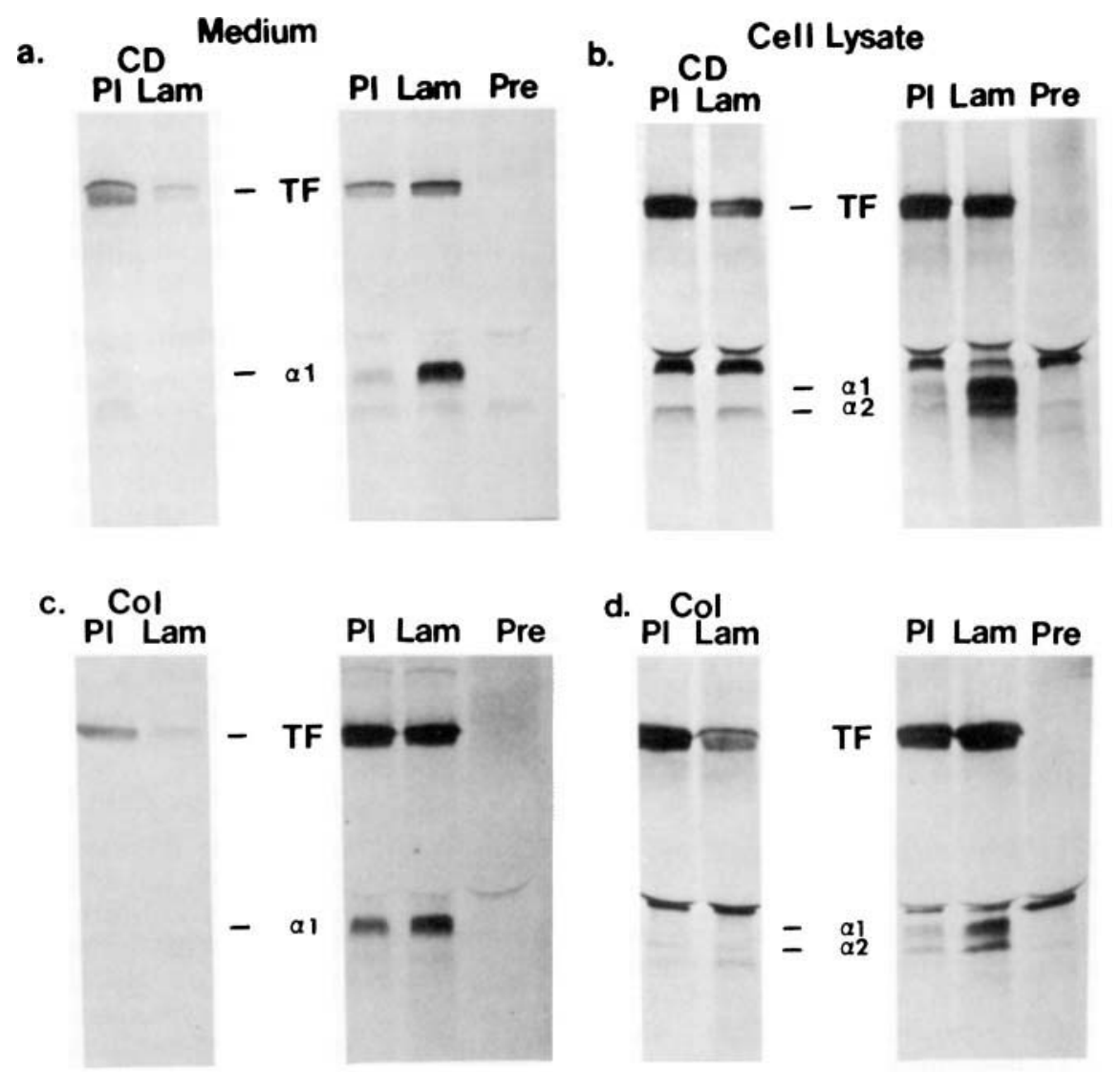

Fig. 1. Immunoprecipitation of $\left.{ }^{35} \mathrm{~S}\right]$-methionine labeled cultures treated with cytochalasin $\mathrm{D}$ and colchicine. Mammary cells were maintained in culture on plastic or laminin coated dishes for 6 days, then treated with cytochalasin $\mathrm{D} 2 \mu \mathrm{M}$ or colchicine $1 \mu \mathrm{M}$ for $24 \mathrm{~h}$. The cultures were metabolically labeled with $\left.{ }^{35} \mathrm{~S}\right]$-methionine for $1 \mathrm{~h}$, and the medium and cell lysates were harvested as described under Materials and Methods. Equivalent TCA precipitable counts of [ $\left.{ }^{35} \mathrm{~S}\right]$-methionine labeled medium (a and $\mathbf{c}$ ) and cell lysates (b and $\mathbf{d}$ ) from these cultures were immunoprecipitated, electrophoresed, dried, and fluorograms were obtained. P1, plastic; Lam, laminin; CD cytochalasin D; Col, colchicine; Pre, pre-immune control; TF, transferrin; $\alpha 1, \alpha 1$ casein; $\alpha 2, \alpha 2$ casein.

tion at multiple levels including protein stability and secretion and mRNA accumulation. We therefore examined the effects of cytoskeletal inhibitors on milk protein turnover and secretion. We then determined the effects of these agents on the steady state accumulation of mRNAs for these proteins.

\section{Protein stability and secretion}

In order to determine whether cytoskeletal inhibitors affected milk protein stability and/or secretion, cultures on laminin were pulsed with $\left[{ }^{35} \mathrm{~S}\right]$-methionine and cytochalasin $\mathrm{D}$ was added during the chase period. As shown in Figure 6a,b, cytochalasin $\mathrm{D}$ added during the chase period had no significant effect on intracellular turnover of $\alpha$-casein or transferrin. This treatment resulted in an increase in the secretion of these proteins during the first hour of the chase. From these experiments, it is clear that the marked reduction in milk protein gene expression resulting from cytochalasin D treatment is not due to increased protein turnover or decreased secretion.

\section{mRNA accumulation}

In order to determine whether the decrease in milk protein gene expression resulting from cytoskeletal inhibitors was due to decreased mRNA accumulation for these proteins, we performed Northern blot analysis. Total cellular RNA was isolated from cultures on laminin or tissue culture plastic substratum in the presence or absence of cytoskeletal inhibitors. The RNA was electrophoresed, transferred to nitrocellulose, and probed with ${ }^{32} \mathrm{P}$-labeled cDNAs for $\alpha$-casein, transferrin, and $\alpha$-lactalbumin. As shown in Figure 7a, intact mRNAs for $\alpha$-casein $(1.4 \mathrm{~kb})$, transferrin $(2.4$ $\mathrm{kb}$ ), and $\alpha$-lactalbumin (785 bp) were identified by this technique. As can be seen, the steady state levels of the milk protein mRNAs were increased on laminin compared to tissue culture plastic. Furthermore, both cytochalasin $\mathrm{D}$ and colchicine caused a marked reduction in the steady state levels of mRNA for each of the milk protein genes. In the presence of these inhibitors steady state levels of mRNA on laminin substrata were considerably below those found on tissue culture plastic in the absence of cytoskeletal inhibitors. Cytochalasin D or colchicine reduced $\alpha$-casein mRNA steady state levels to $10 \%$ that on tissue culture plastic and transferrin to $40 \%$ of that on tissue culture plastic. mRNA for $\alpha$-lactalbumin was undetectable after cytochalasin D treatment. These experiments suggest that the effects of the cytoskeletal disrupting agents on 
a a 1 CASEIN

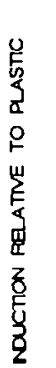

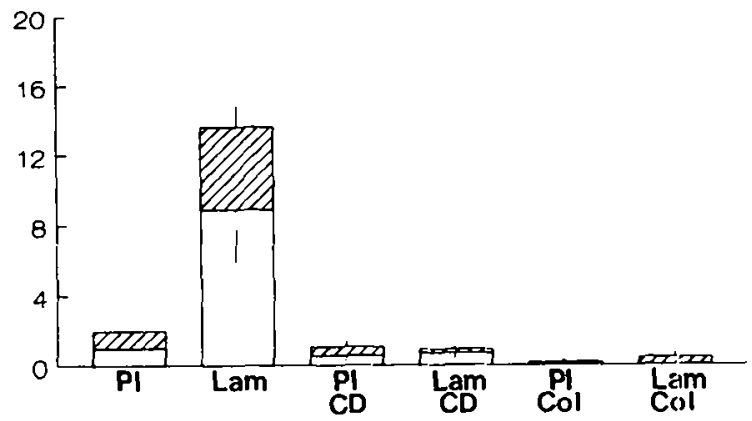

b

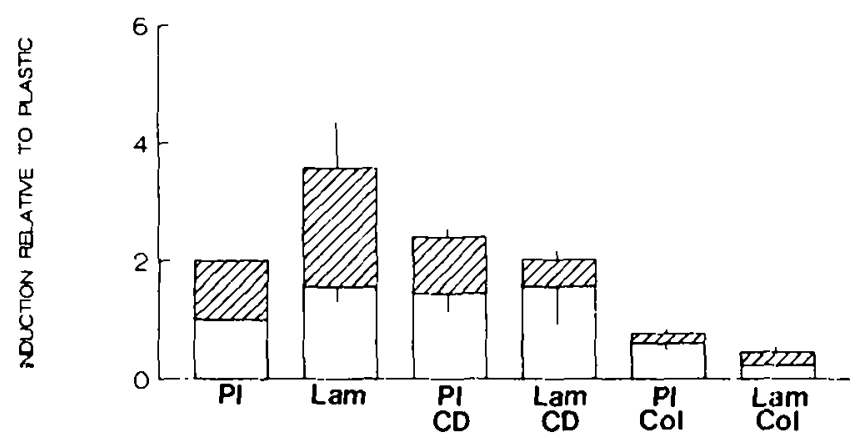

Fig. 2. $\alpha$-Casein and transferrin synthesis. SDS polyacrylamide gels from experiments performed as described in Figure 1 were analyzed by excising the bands, solubilizing in $\mathrm{H}_{2} \mathrm{O}_{2}$ at $100^{\circ} \mathrm{C}$ for $2 \mathrm{~h}$, and counting in Beckman Ready-Solve-MP as described under Materials and Methods. The mean amount of induction of a) $\alpha$-casein and b) transferrin relative to that of cells on plastic dishes is shown. A unit of 1 is assigned to each of the medium and cell lysate on tissue culture plastic. P1, tissue culture plastic; Lam, laminin; CD, cytochalasin D; Col, colchicine. Values are the mean of 3 to 4 experiments. Error bars indicate the standard error of the mean. $\square$, cell lysates; $\square$, medium.

laminin induced milk protein gene expression occur predominantly at the level of accumulation of mRNAs for these proteins.

\section{Effect of the cytoskeleton on cell shape}

Previous investigators studying mammary differentiation have suggested that cell shape plays a role in milk protein gene expression. These studies, predominantly using cells on floating collagen gels, have suggested that a rounded cell morphology is necessary for the expression of milk protein genes (Haeuptle et al., 1983; Shannon and Pitelka, 1981). In the current study we have found that cytoskeletal disrupting agents block milk protein gene expression despite the fact that they induce a more rounded morphology. As shown in Figure $8 b$, cytochalasin $D$ treatment causes cell rounding along with depolymerization of the actin cytoskeleton. Colchicine treatment causes collapse of the normal trabecular pattern of tubulin as well as rounding as shown in Figure 8d. Despite a rounded morphologic appearance, milk protein gene expression is inhibited. a LACTALBUMIN

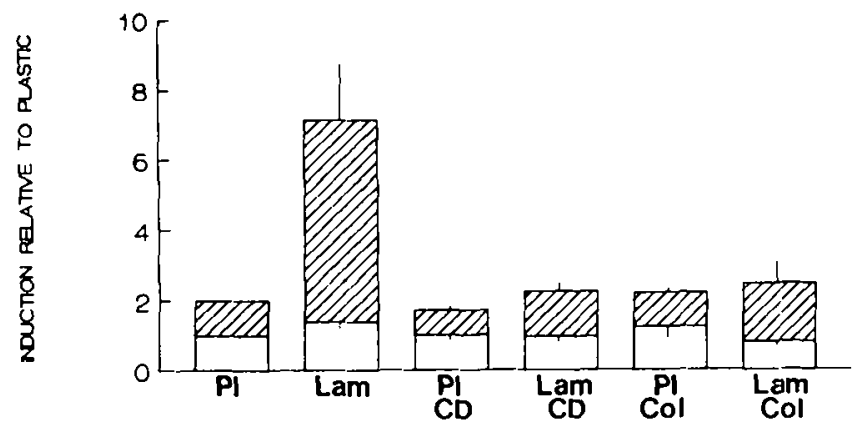

Fig. 3. $\alpha$-Lactalbumin synthesis. The mean amount of induction of $\alpha$-LA synthesis relative to that of cells on plastic from 4 to 9 experiments based on a radioimmunoassay and normalized for cell number. P1, tissue culture plastic; Lam, laminin; CD, cytochalasin D; $\mathrm{Col}$, colchicine. Error bars indicate the standard error of the mean. $\square$, cell lysates; $\square$, medium.

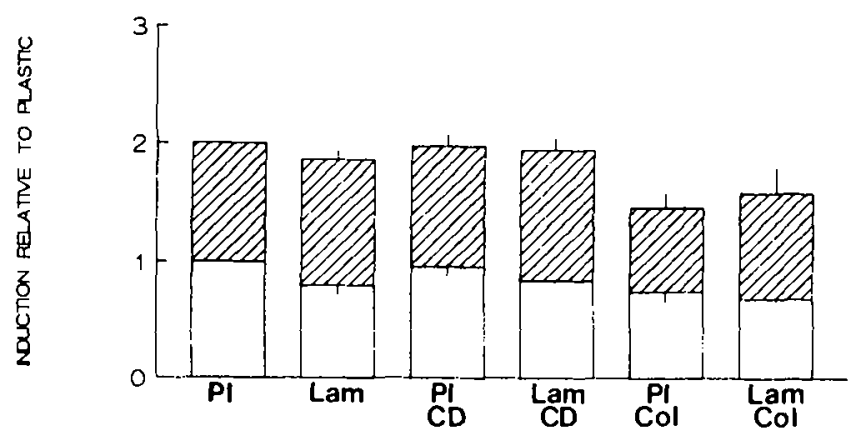

Fig. 4. Total protein synthesis. Medium and cell lysates were harvested from [ $\left.{ }^{35} \mathrm{~S}\right]$-methionine labeled cultures as described under Material and Methods and in Figure 1. Duplicate aliquots were utilized for TCA precipitation. The mean amount of induction of TCA precipitable counts relative to that of cells on plastic from 3 to 9 separate experiments and normalized for cell number. P1, tissue culture plastic; Lam, laminin; CD, cytochalasin D; Col, colchicine. Error bars indicate the standard error of the mean. $\square$, cell lysates; $\nabla$, medium.

\section{DISCUSSION}

In this paper we have demonstrated in primary rat mammary cultures that expression of milk protein genes requires an intact cytoskeleton. Induction of these genes by the basement membrane glycoprotein laminin is abrogated by the cytoskeletal inhibitors, cytochalasin D or colchicine. Moreover, the degree of inhibition of milk protein gene expression parallels the magnitude of induction by laminin. Thus, $\alpha$-casein which shows the largest induction by laminin is maximally inhibited by cytoskeletal inhibitors. Conversely, transferrin which demonstrates only a modest induction by laminin shows the least inhibition by these agents. Although the primary actions of these two agents are to disrupt the actin and microtubule cytoskeletons, additional effects on cells may be mediated by these agents. The primary action of cytochalasin D is to inhibit the polymerization of actin by binding to the fast growing or end of actin filaments as shown by Brown and Spudich (1979) and Flanagan and Lin (1980). Additionally, Schliwa (1982) has shown that 
a.

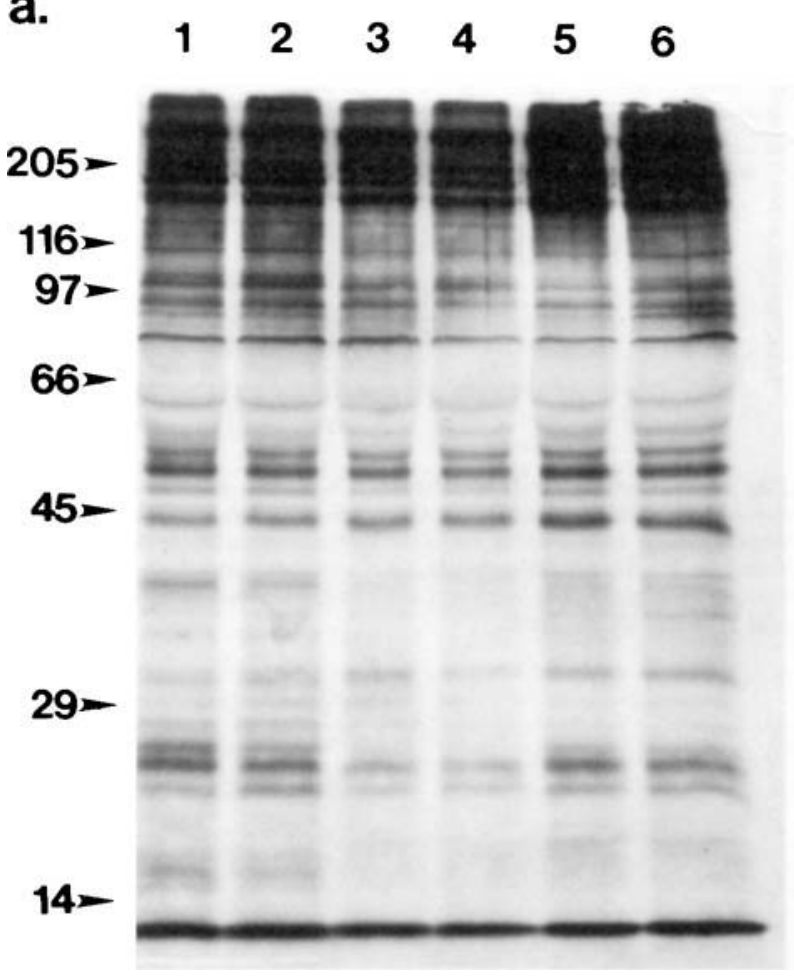

Fig. 5. SDS-PAGE of synthesized proteins. Medium and cell lysates were harvested from [ $\left.{ }^{35} \mathrm{~S}\right]$-methionine labeled cultures as described under Materials and Methods and in Figure 1. Equivalent numbers of TCA precipitable counts of a) medium and b) cell lysates were

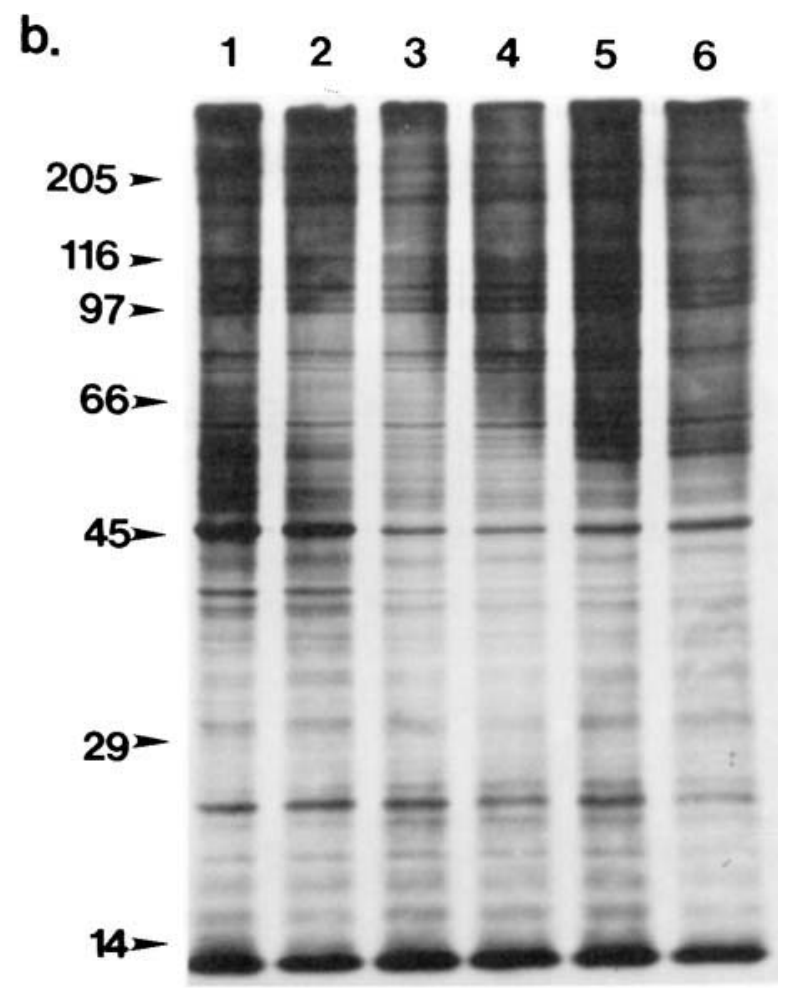

electrophoresed on $10 \%$ polyacrylamide gels, dried, and fluorograms obtained. Lanes 1) plastic and 2) laminin were treated with cytochalasin D, lanes 3) plastic and 4) laminin were treated with colchicine, lanes 5) plastic and 6) laminin were untreated controls. cytochalasin $\mathrm{D}$ inhibits the formation of a network of cytoskeleton filaments. Unlike other cytochalasins, cytochalasin $\mathrm{D}$ has no effect on hexose transport, as demonstrated by Rampal et al. (1980), and was therefore utilized for these studies. Inhibition of the networking and polymerization of the actin cytoskeleton has additional effects on cells as shown by Unemori and Werb (1986). In rabbit synovial fibroblasts, cytochalasin $\mathrm{B}$ treatment decreases collagen and increases collagenolytic activity, suggesting that the cytoskeleton plays a role in the remodeling of the ECM in that cellular system. Similarly, although the primary action of colchicine is to bind to tubulin, preventing microtubule formation as shown by Weisenberg et al. (1968), Deery and Weisenberg (1981), and Andreu and Timasheff (1986), additional effects on cells may result since the microtubule network is involved in multiple cellular events.

We further show that treatment with cytochalasin D and colchicine selectively inhibits milk protein gene expression without significant effect on general protein synthesis. As demonstrated by quantitation of total protein synthesis and by gel electrophoresis, treatment with cytochalasin $\mathrm{D}$ or colchicine has no major effect on the majority of synthesized proteins associated with the cell layer or secreted into the medium. These studies are particularly useful since many proteins can be examined simultaneously. These results are in contrast with our findings for the milk proteins which are significantly reduced by these cytoskeletal inhibitors. Taken together these studies demonstrate that the effect of these agents on milk proteins are not due to toxic effects or to general effects on protein synthesis.

We have previously demonstrated that the effects of laminin on milk protein gene expression occurred at multiple levels including mRNA accumulation, protein stability and secretion. The effects of cytoskeleton inhibitors on blocking milk protein gene expression appear to be due to the effects of these compounds on mRNA accumulation rather than effects on protein stability or secretion. Indeed, pulse chase experiments in which cytochalasin $\mathrm{D}$ was added during the chase period demonstrate that this compound causes a release of previously synthesized $\alpha$-casein and transferrin into the medium. This increased secretion in the presence of cytochalasin D is similar to the reported effect of this compound in promoting secretion in granulocytes (Lew et al., 1986) and in adrenal chromaffin cells (Lelkes et al., 1986).

The effect of cytoskeletal inhibitors on steady state mRNA accumulation could be due to changes in transcription rate and/or mRNA stability. Preliminary experiments in our laboratory indicate that the predominant effects of both laminin and cytoskeletal inhibitors on milk protein mRNA accumulation occur at 
a. a 1 CASEN

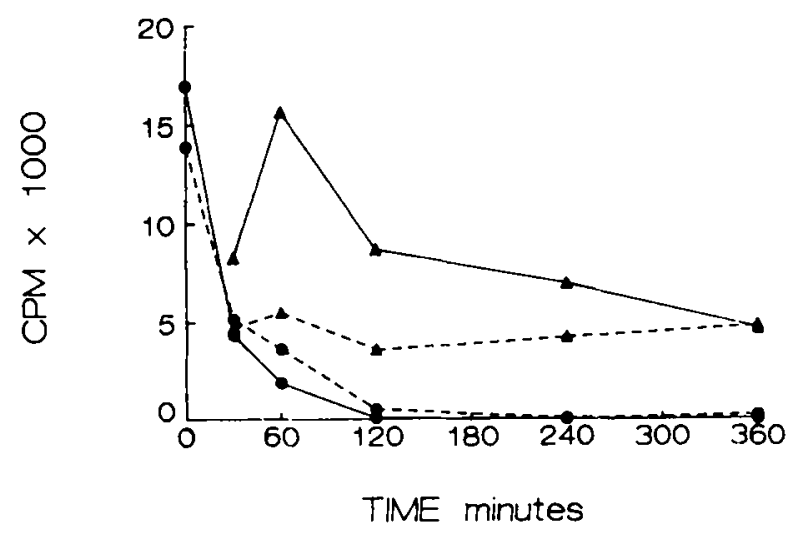

b. TRANSFERRIN

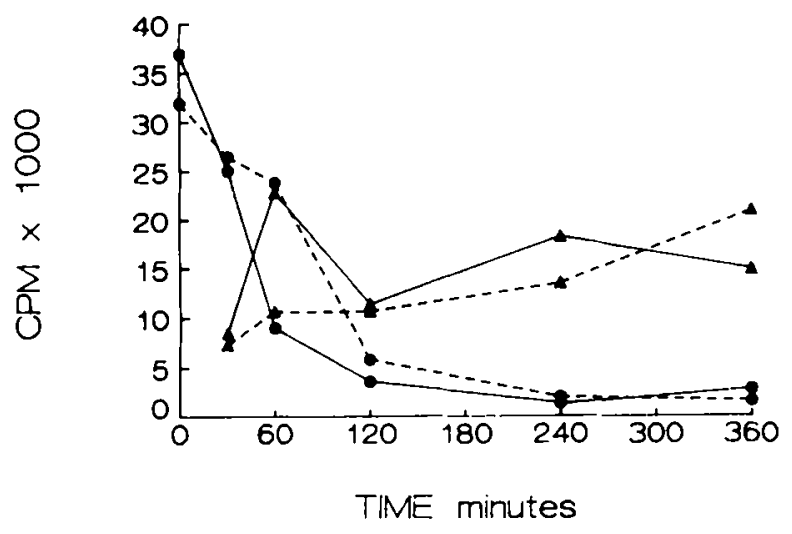

Fig. 6. Effect of cytochalasin D on the kinetics of $\alpha 1$-casein and transferrin synthesis and secretion. Day 6 cultures on laminin were incubated for $1 \mathrm{~h}$ in methionine-free medium, pulsed with $200 \mu \mathrm{Ci} / \mathrm{ml}$ $\left.{ }^{36} \mathrm{~S}\right]$-methionine for $1 \mathrm{~h}$ at $37^{\circ} \mathrm{C}$, washed once with medium containing an excess of unlabeled methionine and then chased for the indicated times in the presence (-) or absence (......) of cytochalasin D. Medium and cell lysates were harvested, immunoprecipitated, electrophoresed, dried, and fluorograms were obtained. The bands were cut from the gels, and analyzed as described under Materials and Methods and in Figure 2. a) $\alpha 1$-casein and b) transferrin show the kinetics in the laminin cell lysate $(-\infty)$ secreted on laminin $(\boldsymbol{\Delta}-\mathbf{A})$, in the laminin cell lysate in the presence of cytochalasin $D(0-0)$, and secreted on laminin in the presence of cytochalasin $D(\Delta-\Delta)$.

the level of mRNA turnover (manuscript in preparation). This suggests that the cytoskeleton may serve to stabilize mRNA species. Walker and Whitfield (1985) have previously shown that mRNAs and polysomes are associated with the cytoskeleton. Furthermore, Penman and colleagues have demonstrated that treating cells with cytochalasin D releases mRNA from the cytoskeleton and reduces protein synthesis (Cervera et al., 1981; Lenk et al., 1977; Ornelles et al., 1986). Bonneau et al. (1985) have also provided evidence for association of specific mRNAs with the cytoskeleton. In our system, steady state mRNA levels may reflect mRNA stabilization by the cytoskeleton. The observation that cytoskeletal inhibitors affect the expression of
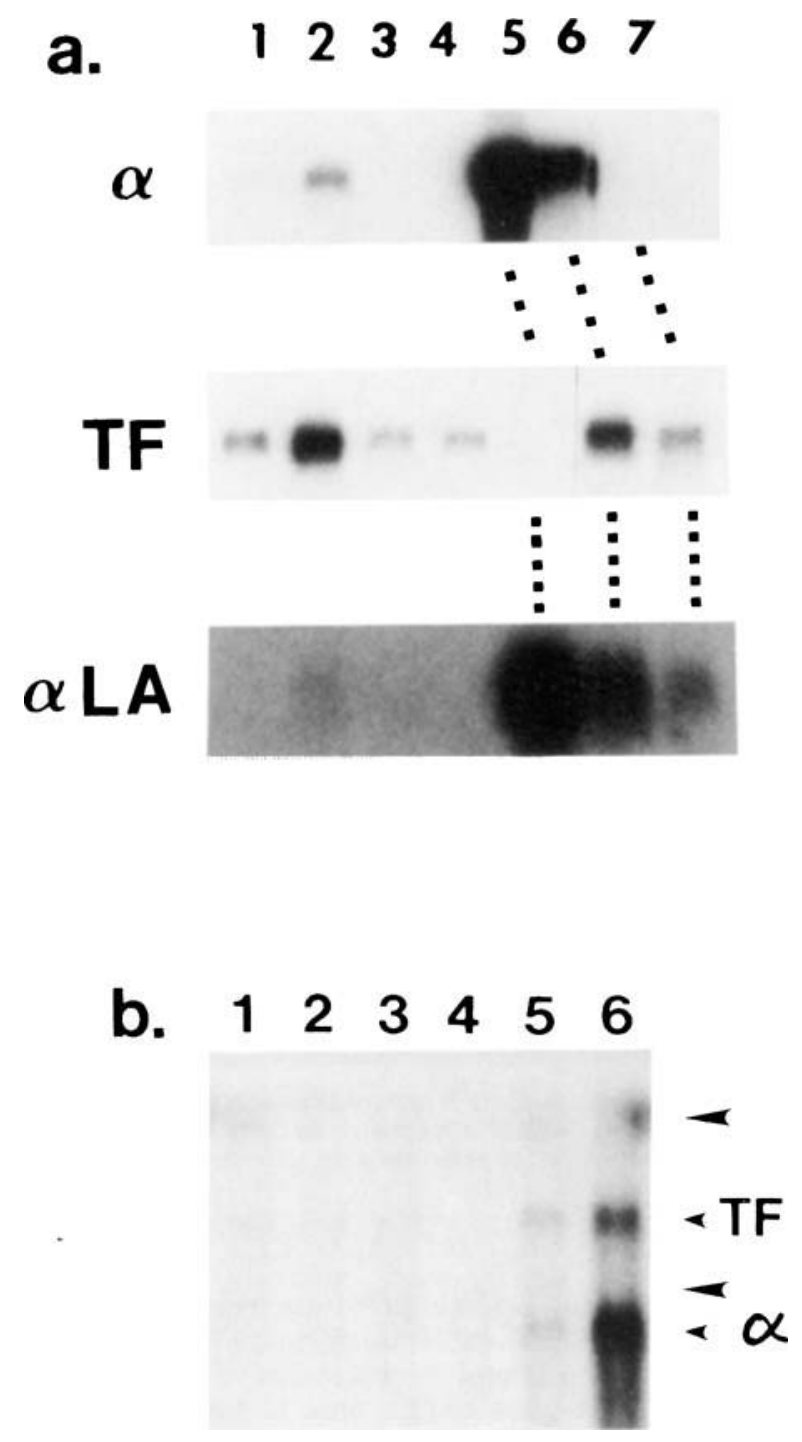

Fig. 7. Northern blot analysis. RNA isolated from primary rat mammary cells cultured on plastic or laminin in the presence or absence of cytoskeleton inhibitors, was size fractionated on formaldehyde-agarose gels, transferred to nitrocellulose, and hybridized to ${ }^{32} \mathrm{P}$ nick translated cDNAs for rat $\alpha$-casein, rat transferrin, and mouse $\alpha$-lactalbumin. Equal amounts of RNA $(4 \mu \mathrm{g})$ were loaded in each lane. a) lanes 1) plastic and 2) laminin controls; 3) plastic and 4) laminin treated with cytochalasin $D, 5$ ), lactating mammary gland RNA; 6), perphenazine stimulated mammary gland RNA; 7) virgin mammary gland RNA. b) lanes 1) plastic and 2) laminin treated with cytochalasin D; 3) plastic and 4) laminin, treated with colchicine; 5) plastic and 6) laminin controls. TF, transferrin mRNA, $2.4 \mathrm{~kb} ; \mathrm{a}$, $\alpha$-casein mRNA, $1.4 \mathrm{~kb}$, and $\alpha$-LA, $\alpha$-lactalbumin mRNA $785 \mathrm{bp}$. The large arrowheads indicate the position of the $28 \mathrm{~S}$ and $18 \mathrm{~S}$ ribosomal bands.

a small subset of total proteins suggests that there may be selective association of specific mRNAs with the cytoskeleton. Alternately, the selective effects of the cytoskeletal inhibitors may reflect intrinsic differences in the stability of mRNAs released by depolymerization of the cellular cytoskeleton. Experiments to distinguish these possibilities are in progress. 

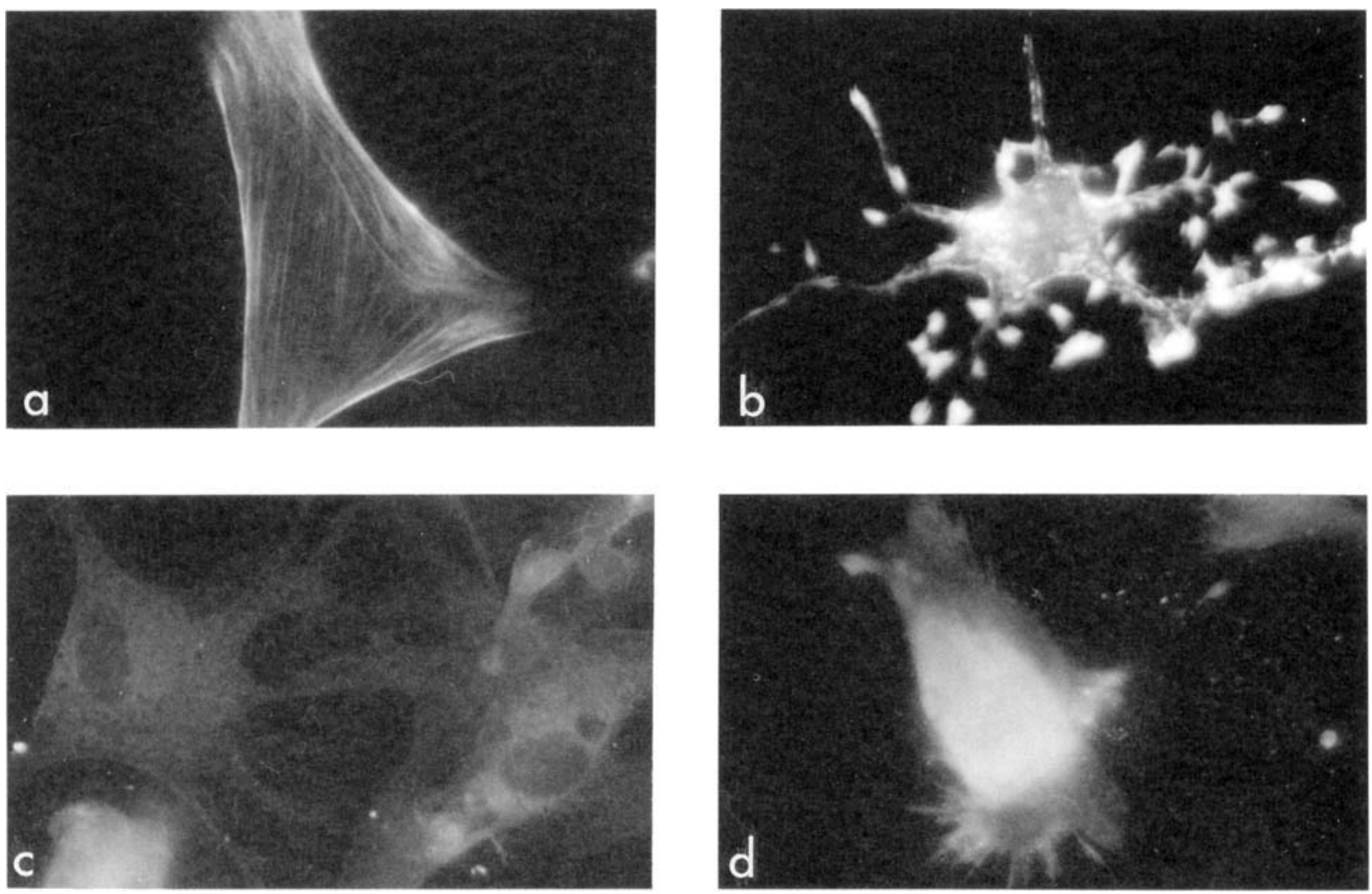

Fig. 8. Effect of cytochalasin D and colchicine on the cytoskeleton and cell shape. Mammary cells were maintained on laminin for 6 days, then treated wtih cytochalasin D or colchicine for $24 \mathrm{~h}$. Actin ( $\mathbf{a}$ and $\mathbf{b}$ ) was visualized by treatment with rhodamine conjugated phalloidin. Tubulin (c and d) was visualized by indirect immunofluorescence. a) control cells, b) cells treated with cytochalasin D, c) control cells, d) cells treated with colchicine. $\times 630$.

In our system, unlike previous reports in rabbit organ culture studies by Houdebine and Djiane (1980), both cytochalasin $D$ and colchicine have similar effects on milk protein gene expression. Cytochalasin D affects actin polymerization while colchicine affects tubulin. These results may indicate that expression of laminin induced milk protein genes requires both an intact actin and microtubule cytoskeleton. By light microscopic immunofluorescence we have not detected any major structural alterations in the actin cytoskeleton with colchicine treatment, nor have we observed depolymerization of microtubules with cytochalasin D treatment (data not shown). However, actin and microtubules are known to interact in vitro via MAP-2 (Selden and Pollard, 1986) and subtle interactions between these filament systems might not be detectable by immunofluorescence. Thus, it remains to be determined whether actin and microtubule effects on milk protein gene expression occur independently or through a common mechanism.

In the mammary gland and other systems, it has been suggested that cell shape plays a role in gene expression (Aggeler et al., 1984; Benya and Shaffer, 1982; Haeuptle et al., 1983; Shannon and Pitelka, 1981; Spiegelman and Ginty, 1983; Zanetti and Solursh, 1984). Studies by Shannon and Pitelka (1981) and Haeuptle et al. (1983) utilizing mammary cells on floating collagen gels have demonstrated that a rounded cell shape is associated with secretory differentiation. In our studies, cytoskeletal inhibitors block the expression of milk protein genes despite the fact that these agents induced a rounded cell shape in mammary cells. This indicates that cell shape change alone is insufficient to induce differentiation. Rather, our data suggest the possibility that the effects of cell shape on differentiation may require (or be mediated by) the cellular cytoskeleton. Additionally, Parry et al. (1987) have suggested that the organization of cell polarity by matrix components may participate in the induction of differentiation in mammary cultures. $\mathrm{Cy}-$ toskeleton inhibitors may disrupt normal polarity, leading to a decrease in milk protein gene expression.

We and others (Huard et al., 1986; Lesot et al., 1983; Malinoff and Wicha, 1983; Terranova et al., 1983; Yoon et al., 1987) have previously shown that laminin interacts with a variety of cells via a high affinity $68 \mathrm{kDa}$ cell surface receptor which is also capable of interacting with actin (Brown et al., 1983; Cody and Wicha, 1986). Other ECM receptors have also been shown to interact with the cytoskeleton (Horwitz et al., 1986; Lacy and Underhill, 1987; Rapraeger et al., 1986). This may prove to be a common mechanism through which ECM components affect differentiation. We postulate that the effects of laminin on mammary differentiation might be mediated by the cellular cytoskeleton via the laminin receptor. The findings in this report are con- 
sistent with such a model with the predominant effects occurring at the level of mRNA accumulation. The use of this in vitro system should allow us to further elucidate the molecular mechanisms by which extracellular matrix components affect gene expression.

\section{ACKNOWLEDGMENTS}

We acknowledge the excellent technical assistance of Mr. George Lowrie. In addition, we thank Dr. Jeffrey Rosen for providing the $\alpha$-casein plasmid cDNA clone, Dr. Lola Reid for the transferrin cDNA plasmid clone, and Dr. Mihir Banerjee for the $\alpha$-lactalbumin plasmid cDNA clone. We thank Dr. Samir Hanash and Dr. John Strahler, and Dorothy Walsh for assistance with two dimensional gel electrophoresis. We also thank Drs. Suzanne Suchard and Mary Zeigler for helpful discussions.

This work was supported by grants GM-37091 and F32 HD-06710 from the National Institutes of Health and by BC-357 from the American Cancer Society.

\section{LITERATURE CITED}

Aggeler, J., Frisch, S.M., and Werb, Z. (1984) Changes in cell shape with collagenase gene expression in rabbit synovial fibroblasts. J. Cell Biol., 98:1662-1671.

Andreu, J.M., and Timasheff, S.N. (1986) Tubulin-colchicine interactions and polymerization of the complex. Ann. New York Acad. of Sci., 466:676-689.

Benya, P.D., and Shaffer, J.D. (1982) Dedifferentiated chondrocytes reexpress the differentiated collagen phenotype when cultured in agarose gels. Cell, 30:215-224.

Blum, J.L., Zeigler, M.E., and Wicha, M.S. (1987) Regulation of rat mammary gene expression by extracellular matrix components. Exp. Cell Res., 173:322-340.

Bonneau, A-M., Darveau, A., and Sonenberg, N. (1985) Effect of viral infection on host protein synthesis and $\mathrm{mRNA}$ association with the cytoplasmic cytoskeletal structure. J. Cell Biol., 100:1209-1218.

Brown, S.S., Malinoff, H.L., and Wicha, M.S. (1983) Connectin: Cell surface protein that binds both laminin and actin. Proc. Natl. Acad. Sci. U.S.A., 80.5927-5930.

Brown, S.S., and Spudich, J.A. (1979) Cytochalasin inhibits the rate of elongation of actin filament fragments. J. Cell Biol., 83:657-662.

Cervera, M., Dreyfus, G., and Penman, S. (1981) Messenger RNA is translated when associated with the cytoskeletal framework in normal and VSV-infected HeLA cells. Cell, 23:113-120.

Chirgwin, J., Przbyla, A., MacDonald, R., and Nutter, W. (1979) Isolation of biologically active ribonucleic acid from sources enriched in ribonuclease. Biochemistry, 18:5294-5299.

Cody, R.L., and Wicha, M.S. (1986) Clustering of cell surface laminin enhances its association with the cytoskeleton. Exp. Cell Res. 165:107-116

Deery, W.J., and Weisenberg, R.C. (1981) Kinetic and steady-state analysis of microtubules in the presence of colchicine. Biochemistry, 20:2316-2324.

Flanagan, M.D., and Lin, S. (1980) Cytochalasins block actin filament elongation by binding to high affinity sites associated with F-actin. J. Biol. Chem., 255:835-838.

Haeuptle, M-T., Suard, Y.L.M., Bogenmann, E., Reggio, H., Racine, L., and Kraehenbuhl, J-P. (1983) Effect of cell shape change on the function and differentiation of rabbit mammary cells in culture. $J$. Cell Biol., 96:1425-1434.

Horwitz, A., Duggan, K., Buck, C., Beckerle, M.C., and Burridge, K. (1986) Interaction of plasma membrane fibronecton receptor with talin a transmembrane linkage. Nature, 320:531-533.

Houdebine, L-M., and Djiane, J. (1980) Effects of lysomotropic agents, and of microfilament-and microtubule-disrupting drugs on the activation of casein-gene expression by prolactin in the mammary gland. Mol. and Cell. Endocrin., 17:1-15.

Huard, T.K., Malinoff, H.L., and Wicha, M.S. (1986) Macrophages express a plasma membrane receptor for basement membrane laminin. Am. J. Pathol., 123:365-370.

Lacy, B.E., and Underhill, C.B. (1987) The hyaluronate receptor is associated with actin filaments. J. Cell Biol., 105:1395-1404.
Laemmli, U.K. (1970) Cleavage of structural proteins during the assembly of the head of bacteriophage T4. Nature, 227:680-685.

Lelkes, P. I., Friedman, J.E., Rosenheck, K, and Oplatka, A. (1986) Destabilization of actin filaments as a requirement for the secretion of catecholamines from permeabilized chromaffin cells. FEBS Lett., 208:357-363.

Lenk, R., Ransom, L., Kaufman, Y., and Penman, S. (1977) A cytoskeletal structure with associated polyribosomes obtained from HeLA cells. Cell, 10:67-78.

Lesot, H., Kuhl, U., and von der Mark, K. (1983) Isolation of a laminin-binding protein from muscle cell membranes. EMBO J., 2:861-865.

Lew, P.D., Monod, A., Waldvogel, F.A., Dewald, B., Baggiolini, M. and Pozzan, T. (1986) Quantitative analysis of the cytosolic free calcium dependency of exocytosis from three subcellular compartments in intact human neutrophils. J. Cell Biol., 102:2197-2204.

MacLean-Fletcher, S., and Pollard, T.D. (1980) Mechanism of action of cytochalasin B on actin. Cell, 20:329-341.

Malinoff, H.L., and Wicha, M.S. (1983) Isolation of a cell surface receptor protein for laminin from murine fibrosarcoma cells. J. Cell Biol., 96:1475-1479.

Maniatis, T., Fritsch, E.F., and Sambrook, J. (1982) Molecular Cloning: A Laboratory Manual. Cold Spring Harbor Laboratory, Cold Spring Harbor, New York.

Morrissey, J.H. (1981) Silver stain for proteins in polyacrylamide gels: A modified procedure with enhanced uniform sensitivity Anal. Biochem., 117:307-310.

Ornelles, D.A., Fey, E.G., and Penman, S. (1986) Cytochalasin released mRNA from the cytoskeletal framework and inhibits protein synthesis. Mol. and Cell. Biol., 6:1650-1662.

Parry, G., Cullen, B., Kaetzel, C.S., Kramer, R., and Moss, L. (1987) Regulation of differentiation and polarized secretion in mammary epithelial cells maintained in culture: Extracellular matrix and membrane polarity influences. J. Cell Biol., 105:2043-2051.

Rampal, A.L., Pinkofsky, H.B., and Jung, C.Y. (1980) Structure of cytochalasin and cytochalasin $B$ binding sites in human erythrocyte membranes. Biochemistry, 19:679-683.

Rapraeger, A., Jalkanen, M., and Bernfield, M. (1986) Cell surface proteoglycan associates with the cytoskeleton at the basolateral cell surface of mouse mammary epithelial cells. J. Cell Biol., 103:26832696

Richards, D.A., Rodgers, J.R., Supowit, S.C., and Rosen, J.M. (1981a) Construction and preliminary characterization of the rat casein and $\alpha$-lactalbumin cDNA clones. J. Biol. Chem., 256.526-532.

Richards, D.A., Blackburn, D.E., and Rosen, J.M. (1981b) Restriction enzyme mapping and heteroduplex analysis of the rat milk protein cDNA clones. J. Biol. Chem., 256:533-538.

Schliwa, M. (1982) Action of cytochalasin on cytoskeletal networks. J Cell Biol., 92:79-91.

Selden, S.C., and Pollard, T.D. (1986) Interaction of actin filaments with microtubules is mediated by microtubule-associated proteins and regulated by phosphorylation. Ann. New York Acad. Sci. 466:803-812.

Shannon, J.M., and Pitelka, D.R. (1981) The influence of cell shape on the induction of functional differentiation in mouse mammary cells in vitro. In Vitro, 17:1016-1028.

Spiegelman, B.M., and Ginty, C.A. (1983) Fibronectin modulation of cell shape and lipogenic gene expression in 3T3-adipocytes. Cell $35: 657-666$.

Sugrue, S.P., and Hay, E.D. (1981) Response of basal epithelial cell surface and cytoskeleton to solubilized extracellular matrix molecules. J. Cell Biol., 91:45-54.

Terhorst, C., van Agthoven, A., LeClair, K., Snow, P., Reinherz, E., and Schlossman, S. (1981) Biochemical studies of the human thymocyte cell-surface antigens T6, T9 and T10. Cell, 23:771-780.

Terranova, V.P., Rao, C.N., Kalebic, T., Margulies, I.M., and Liotta, L.A. (1983) Laminin receptor on human breast carcinoma cells. Proc. Natl. Acad. Sci. U.S.A., 80:444-448.

Timpl, R., Rohde, H., Robey, P.G., Rennard, S.I., Foidart, J-M., and Martin, G.R. (1979) Laminin-A glycoprotein from basement membranes. J. Biol. Chem., 254:9933-9937.

Tolleshaug, H., Goldstein, J.L., Schneider, W.J., and Brown, M.S (1982) Posttranslational processing of the $\mathrm{LDL}$ receptor and its genetic disruption in familial hypercholesterolemia. Cell, 30:715724

Unemori, E.N., and Werb, Z. (1986) Reorganization of polymerized actin: A possible trigger for induction of procollagenase in fibroblasts cultured in and on collagen gels. J. Cell Biol., 103:1021-1031.

Walker, P.R., and Whitfield, J.F. (1985) Cytoplasmic microtubules are essential for the formation of membrane-bound polyribosomes. J. Biol. Chem., 260:765-770. 
Weisenberg, R.C., Borisey, G.G., and Taylor, E.W. (1968) The colchicine-binding protein of mammalian brain and its relation to microtubules. Biochemistry, 7:4466-4479.

Wicha, M.S., Lowrie, G., Kohn E., Bagavandoss, P., and Mahn, T. (1982) Extracellular matrix promotes mammary epithelial growth and differentiation in vitro. Proc. Natl. Acad. Sci. U.S.A., 79:32133217 .
Yoon, P.S., Boxer, L.A., Mayo, L.A., Yang, A.Y., and Wicha, M.S. (1987) Human neutrophil laminin receptors: Activation-dependent receptor expression. J. Immunol., 138:259-265.

Zanetti, N.C., and Solursh, M. (1984) Induction of chondrogenesis in limb mesenchymal cultures by disruption of the actin cytoskeleton. J. Cell Biol., 99:115-123. 